\title{
Cross Correlation Studies in Primate Motor Cortex: Event Related Correlation
}

\author{
John T. Murphy, Hon C. Kwan and Yiu C. Wong
}

\begin{abstract}
Simultaneous extracellular unit recordings were made from each cell of 237 pairs in two awake monkeys, during a voluntary reaching movement of the forelimb. The cells were located in contralateral precentral cortex and functionally coupled to single forelimb joints, as indicated by intracortical microstimulation and passive sensory stimulation. Cross correlation analysis showed that 72 of these pairs exhibited significant event-related correlation over periods of up to $780 \mathrm{~ms}$, comparable to and coincident with the forelimb movement. Spatial analysis showed that such correlation extended across contiguous portions of all four forelimb joint zones of precentral cortex, over distances up to $3.5 \mathrm{~mm}$. No preferred direction of correlation was observed. The data confirm the previously described nested organization of the forelimb area of precentral cortex. Findings are discussed in terms of mechanisms by which columns of neurons in motor cortex participate in the reaching movement.
\end{abstract}

RÉSUMÉ: Corrélation entre évenements dans les neurons du cortex moteur des primates Nous avons enregistré simultanément les unités extra-cellulaires de chacune des cellules de 237 paires chez deux singes éveillés et cela durant un mouvement volontaire de préhension de l'avant-bras. Ces cellules étaient situées au cortex précentral contralatéral et étaient unies fonctionnellement à des articulations uniques de l'avant-bras, tel qu'indiqué par la microstimulation intra-corticale et la stimulation sensitive passive. Une analyse de corrélation croisée a montré que chez 72 de ces paires on pouvait identifier une corrélation significative reliée à un événement précis sur des périodes atteignant $780 \mathrm{~ms}$, donc comparables et coîncidentes au mouvement de l'avant-bras. Une analyse spatiale démontre qu'une telle corrélation atteint les portions continguës des 4 zones articulaires des avant-bras dans le cortex précentral et ceci sur des distances atteignant $3,5 \mathrm{~mm}$. Aucune direction préférentielle de cette corrélation ne fut observée. Ces données confirment l'organisation en anneaux nidiformes de l'aire avant-bras du cortex cérébral. Les résultats sont discutées en termes par lesquels des colonnes de neurones du cortex moteur participent au mouvement de préhension.

Can. J. Neurol. Sci. $1985 ; 12: 24-30$

The forelimb region of precentral cortex in primates contains multiple columns of neurons which are functionally coupled to single joints (Kwan et al., 1978; Murphy et al., 1978; Wong et al., 1978). Neurons within these columns discharge in association with voluntary, reaching movements of the forelimb, and such discharges can be triggered by various sensory stimuli (Lemon, 1981; Murphy et al., 1982 a,b; Lamarre et al., 1983). There is a degree of redundancy, with spatially separate columns sharing the same function (Murphy et al., 1978) Neurons in the same and different columns share input from common sources and interact synaptically with each other (Murphy et al., 1985a). In the present study, we employ cross correlation analysis to study the temporal and spatial properties of event-related activation of these columns during a reaching movement.

\section{METHODS}

Recording techniques, the behavioural paradigm and methods of histological reconstruction of recording sites were described in the preceding paper (Murphy et al., 1985a). All neurons were functionally identified by intracortical microstimulation (ICMS) and passive sensory stimulation. Functional properties of each column and cell were defined by the effects of ICMS at the recording site (Murphy et al., 1978). To assess event-related correlation between two neurons in the forelimb area of motor cortex, separate independently controlled microelectrodes were advanced into the forelimb area of motor cortex. Individual spike trains from these neurons were extracellularly recorded during a voluntary reaching movement of the forelimb. Data was gathered from two macaque monkeys.

All order $5 \mathrm{~ms}$ bin cross correlograms were computed from the spike trains for each pair of cells. Frame-shuffling was employed to identify event-related correlations (Perkel et al., 1967). Peaks or valleys above or below the mean background bin count were detected using $\mathrm{p}<0.01$ significance levels. Strength of correlation was calculated based on a t-test statistic ( $z$ value) comparing the means and standard deviations of bin counts in 
bins showing significant correlation with those of background bin counts.

\section{RESULTS}

A total of 237 cell pairs were studied in the two monkeys. Of these, 72 showed significant event-related correlation. Inspection of the correlograms indicated only event-related correlation patterns in 24 of the 72 pairs, while mixtures of this pattern with patterns of synaptic excitation and/or shared input were observed in the remainder (Table 1). Details concerning the latter patterns are described in the preceding report (Murphy et al., 1985a). Event-related correlations were in all cases positive (hill or peak), whereas synaptic and shared input correlations showed various mixtures of positive and negative (valley) patterns.

Data from a cell pair showing event-related correlation is shown in Figure 1. The cells were recorded from two electrodes simultaneously, and located in columns about $1.5 \mathrm{~mm}$ apart which were functionally coupled to contralateral shoulder and wrist, respectively. Microstimulation at the locus of cell 1 produced shoulder abduction, and at the locus of cell 2, wrist flexion. Each cell was activated in the course of the stimulusresponse paradigm (Fig. 1A). Autocorrelograms showed an absence of periodicity of discharge, and the lower background firing of cell 1 (Fig. 1B). The shuffled cross correlogram shows a broad region of significant correlation between -280 and $+280 \mathrm{~ms}$ (Fig. 1C). The distribution is symmetric and approximately centered at zero. The difference correlogram shows no region of significant correlation.

The temporal profiles of all 72 cell pairs which showed eventrelated correlations are shown in Figure $2 \mathrm{~A}$. Some patterns are shifted to the right of zero and some to the left. The centroid of significant correlations for the population is near zero (Fig. 2B). However, $95 \%$ of time delays between the two cells were less than 100 ms. Durations of correlations ranged between 200 and $780 \mathrm{~ms}$, with a mean of $420 \mathrm{~ms}$ (Fig. 2C).

Spatial aspects of event-related correlations are explored in Figures 3-5. Figure 3 shows that the percentage of correlated pairs decrements in monotonic fashion as a function of distance between electrodes. However, strength of correlation was independent of distance (Fig. 4). Zero distance indicates recording of each member of the pair from the same electrode. Correlated pairs were found separated by distances as great as $3.5 \mathrm{~mm}$.

In Figure 5A, we mapped the functional coupling of each cell to a single forelimb joint as determined by ICMS and passive sensory stimulation. The resultant map showed nested zones of cells coupled to single joints which conformed to our previous maps (Murphy et al., 1978). All cells recorded at depth are referred to the surface of precentral cortex. Each dot (single

Table 1: Cross Correlation Patterns

\begin{tabular}{lcc}
\hline \hline & No. of Pairs & $\%$ \\
\cline { 2 - 3 } Event & 24 & 18 \\
Event + Synaptic & 12 & 9 \\
Event + Shared & 16 & 12 \\
Event + Synaptic + Shared & 20 & 15 \\
Synaptic & 39 & 30 \\
Synaptic + Shared & 11 & 8 \\
Shared & 10 & 8 \\
\hline
\end{tabular}

electrode) or solid line represents an event-related pair(s). A sample of uncorrelated pairs is also represented (dashed straight line). Inspection of Figure 5A shows event-related correlation within the same joint zone, between adjacent zones and across one or two zones. Table 2 substantiates the impression that the event-related correlation encompasses each of the forelimb joint zones.

Frequencies of correlation between neurons located in columns controlling the same, adjacent or non-contiguous joints, as determined by ICMS, showed no significant difference (Table $2: 32 \%, 30 \%, 20 \%$ and $30 \%$, respectively, based on non-parametric $\mathrm{X}^{2}$ goodness of fit test at $\alpha=0.05$ (Harnett, 1975). No directional preference along the $x$ or $y$ axes was observed (Fig. 5A). A polar frequency plot showed an approximately equal frequency of correlated pairs in all polar directions (Fig. 5B).

\section{Discussion}

\section{Methodologic Considerations}

Theoretical aspects of the analysis of stochastic point processes are derived particularly from Cox and Lewis (1966). Applications of these techniques to extracellularly recorded spike trains of single neurons have been refined and expanded by a number of workers (Perkel et al., 1967; Moore et al., 1970; Tatton and Sokolove, 1975; Dayhoff and Gerstein, 1983). In particular, frame shuffling of the gross cross correlogram provides insight regarding event-related correlation, separate and distinct from any synaptic interaction or shared input which might be present (Perkel et al., 1967).

Although the technique is difficult to apply to mammalian brains due to the diversity and multiplicity of interconnections, the availability of high speed computational facilities will undoubtedly make this more feasible in the future (Dickson and Gerstein, 1974; Michalski et al., 1983). Allum and co-workers (1982) have successfully done cross correlation analysis on cell pairs recorded from a single electrode in primates during a forelimb task. The present study is the first to use separate independently manipulated recording electrodes in awake behaving primates. This allowed analysis of correlation across virtually the entire expanse of the forelimb area of precentral cortex.

\section{Temporal Patterns}

Slightly less than one third of all cell pairs showed significant event-related correlation (Table 1). Of these, about two thirds showed in addition synaptic interaction or shared input (Murphy et al., 1985). Durations of significant correlation were quite long (Figs. 1, 2) with a mean of $420 \mathrm{~ms}$ (Fig. 2C). This compares,

\begin{tabular}{|c|c|c|c|}
\hline & Studied & Correlated & $\%$ \\
\hline $\begin{array}{r}\text { Same jt (same electrode) } \\
\text { (diff. electrode) }\end{array}$ & $\begin{array}{l}82 \\
60 \\
\end{array}$ & $\begin{array}{l}32 \\
13 \\
\end{array}$ & $\begin{array}{l}44 \\
22 \\
\end{array}$ \\
\hline & 142 & 45 & $\overline{32}$ \\
\hline Adjacent jt & 70 & 21 & 30 \\
\hline Across $1 \mathrm{jt}$ & 15 & 3 & 20 \\
\hline Across 2 jts & 10 & 3 & 30 \\
\hline Total & $\overline{237}$ & $\overline{72}$ & $\overline{30}$ \\
\hline
\end{tabular}


A

PSTH

Cell 1 o
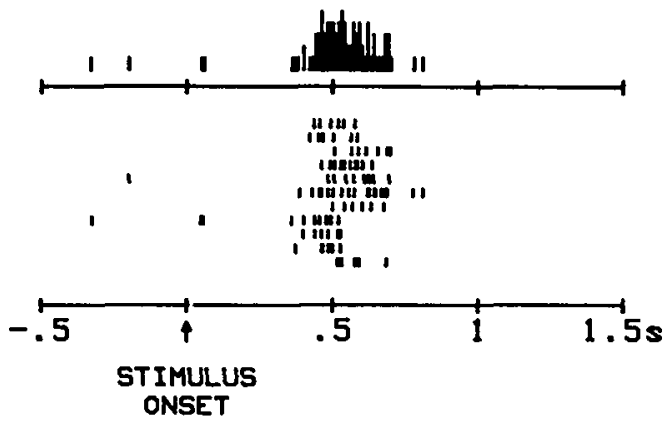

B

AUTOCORRELOGRAMS

Cell 1

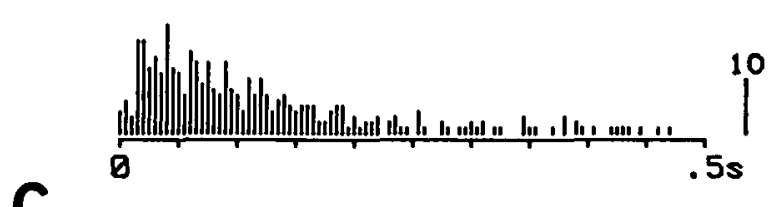

C
Cell 2
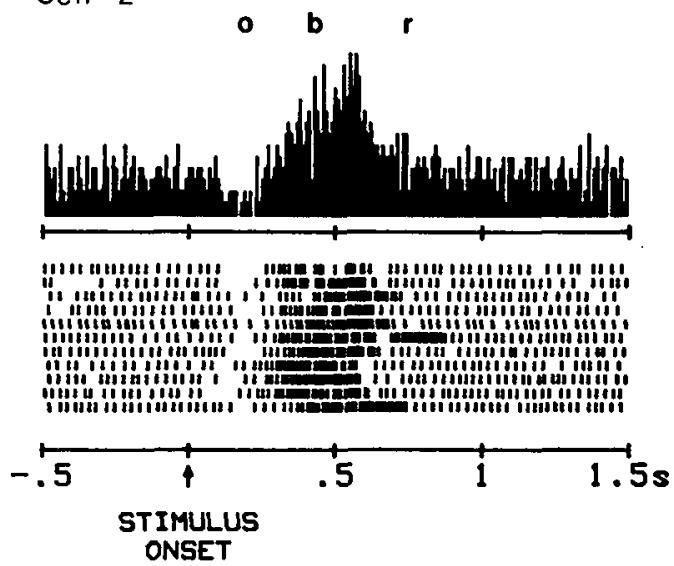

Cell 2

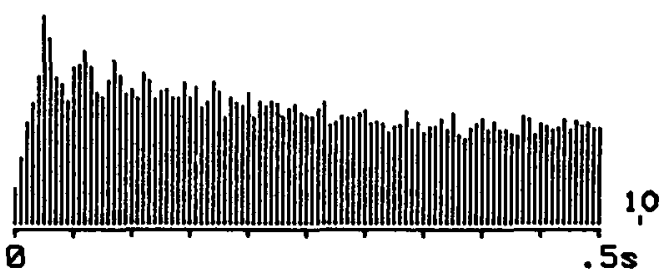

\section{CROSS CORRELOGRAMS $1 \rightarrow 2$}
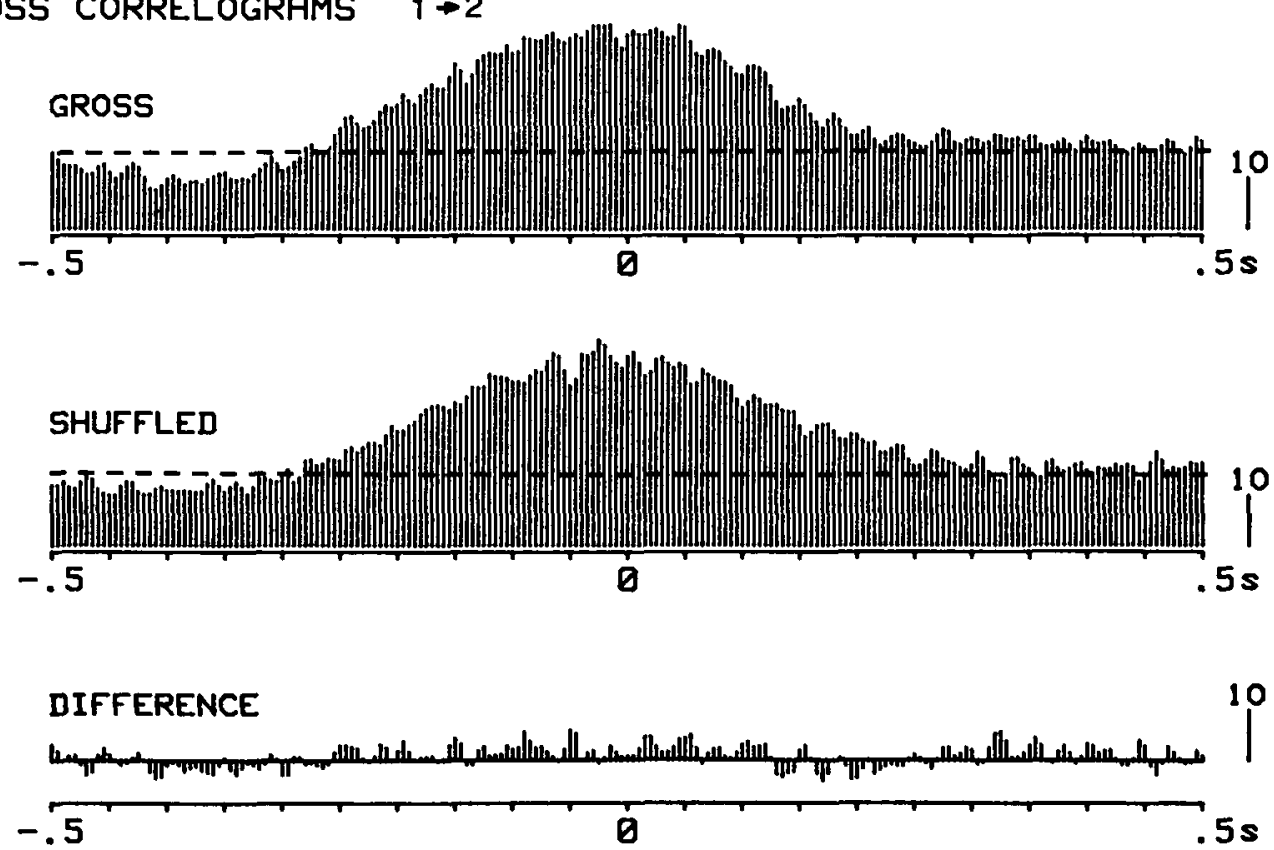

Figure $1-A)$ Peri-stimulus histograms and raster plots (a total of 11 trials) of 2 identified cells recorded simultaneously from separate electrodes. Each vertical bar in the raster represents an action potential. Stimulus onset and approximate times of limb movement onset (o), button touching (b) and returning movement ( $r$ ) are indicated.

B) $5 \mathrm{~ms}$ bin smoothed autocorrelograms of cells 1 and 2. Vertical bar on the right indicates number of counts per bin as shown.

C) $5 \mathrm{~ms}$ bin smoothed cross-correlograms of cell 2 with respect to cell 1. Mean background is indicated by horizontal dashed line. Mean background of difference correlogram is close to zero; and not shown. 
for example, with durations of less than $10 \mathrm{~ms}$ for synaptic interaction and about $260 \mathrm{~ms}$ (median) for shared input (ibid). This duration of event-related correlation is not unexpected since durations of discharge of individual cells in the course of the movement were of similar magnitude (Fig. 1A). Moreover, the time from onset of light stimulus to completion of the reaching movement, i.e. the "event" in this instance, was of similar duration, i.e. about $700-800 \mathrm{~ms}$.

\section{Spatial Patterns}

Mapping of the individual loci of all cells in these two monkeys confirmed the nested arrangement of the forelimb area of motor cortex (Murphy et al., 1978). Event-related correlation was present across the entire surface of the forelimb area of precentral cortex (Fig. 6). The fact that the centroid for the population of correlated pairs was located at zero (Fig. 3B) suggests that spatial sampling was random. For example, a consistent selection of proximal to distal cell pairing for recording channels $\mathrm{A}$ and $B$, respectively, might have biased the centroid away from zero.

A

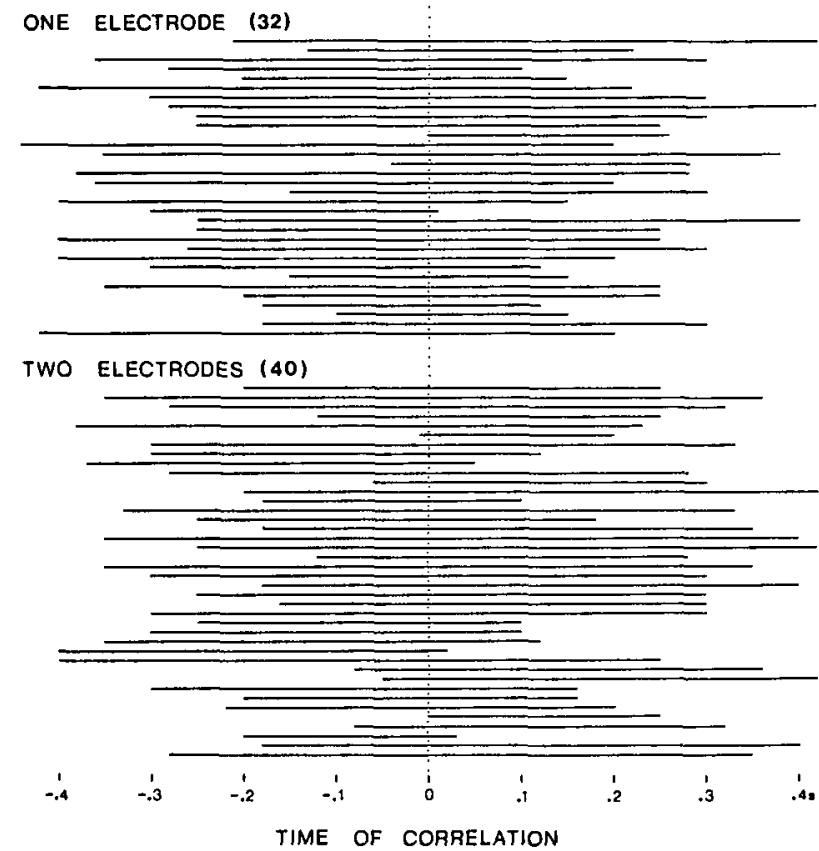

B

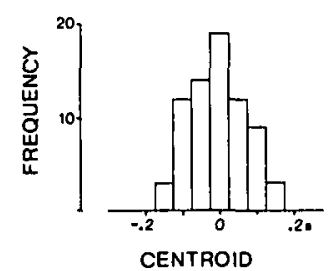

C

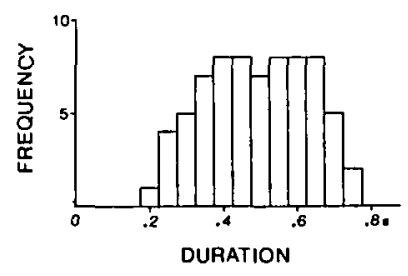

Figure $2-A$ ) Time of correlation of all pairs of correlated cells recorded by one or two electrodes. Time of correlation is defined as the times of occurrence of a hill or peak (solid line) above mean background in the shuffled correlogram.

B) Frequency distribution of centroids of correlation at $50 \mathrm{~ms}$ intervals. C) Frequency distribution of durations of correlation.

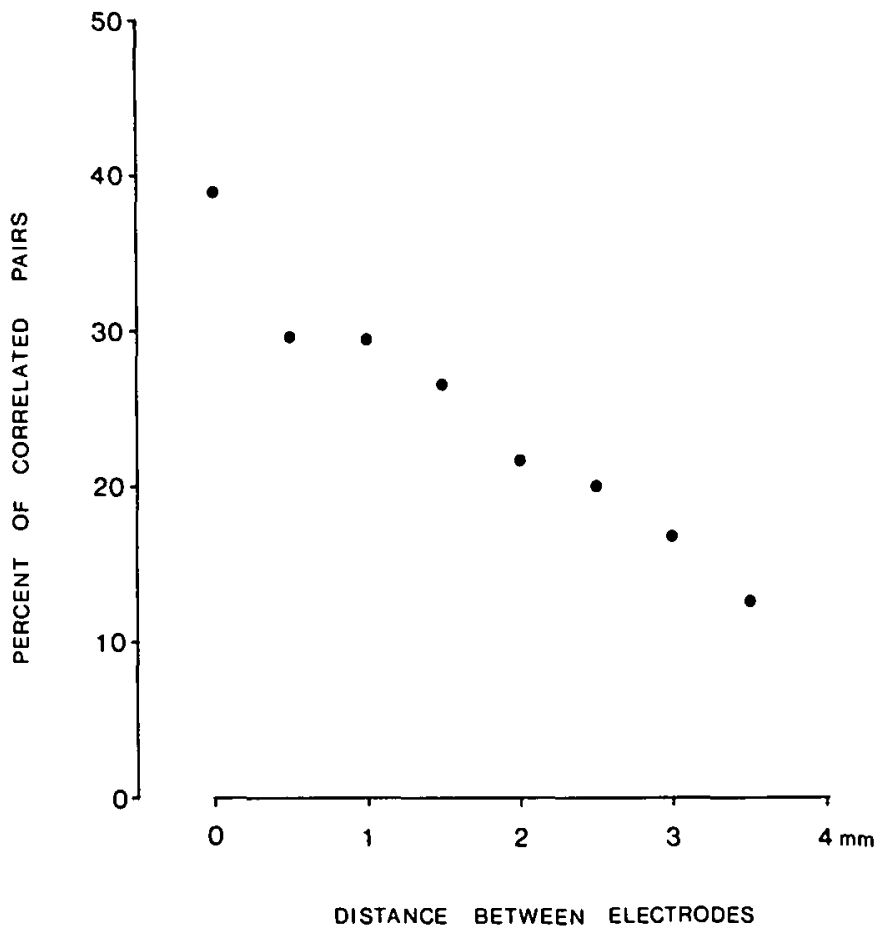

Figure 3 -Distribution of event-related pairs of cells with respect todistances between recording electrodes determined to the nearest $500 \mu$ interval.

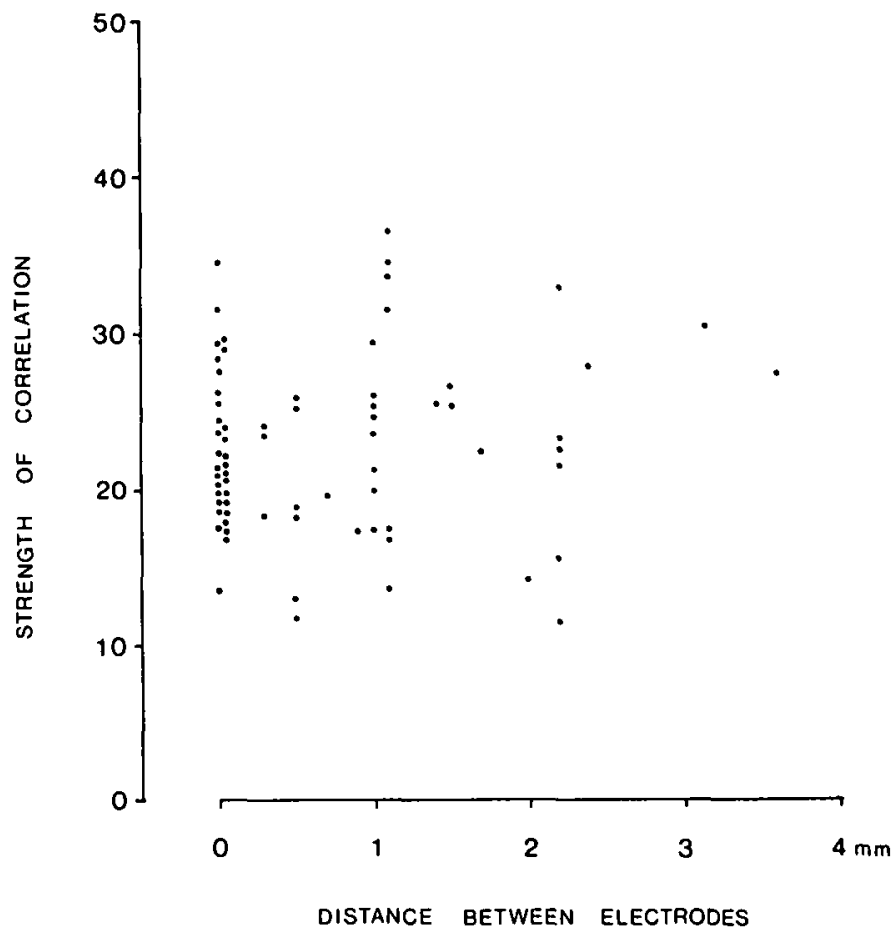

Figure 4 - Strengthof correlation (z value) isplotted against distance between electrodes. Each dot represents a correlated pair of cells. 


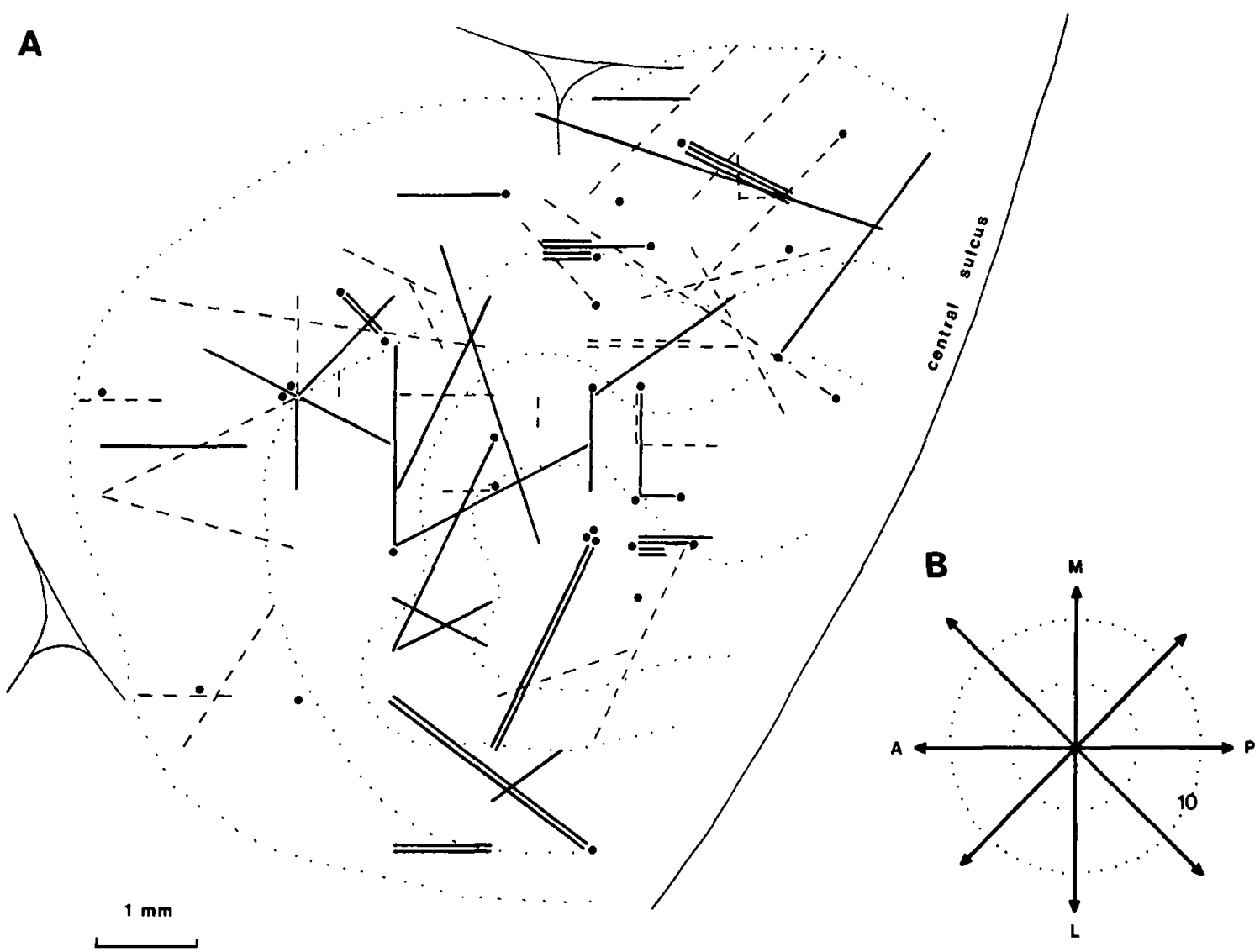

Figure 5-A) Cortical surface map of correlated pairs (solid lines) and uncorrelated pairs (dashed lines). Each solid/dashed line represents one or more pairs. A dot represents correlated pairs of cells recorded by one electrode. Dotted lines demarcate the boundaries of forelimb joint zones: shoulder, elbow, wrist and fingers, in an outer-to-inner order.

B) Frequency distribution of correlated pairs of cells in a given orientation zone $\left(45^{\circ}\right.$ sectors). Percentage is represented by length of the arrow (radius of outer circle $=10 \%)$. Medial $(M) \cdot$ Lateral $(L): 25.6 \%$; Anterior $(A)$ - Posterior (P): 25.7\%; MA-PL: 28.5\%; MP-AL: $25 \%$.

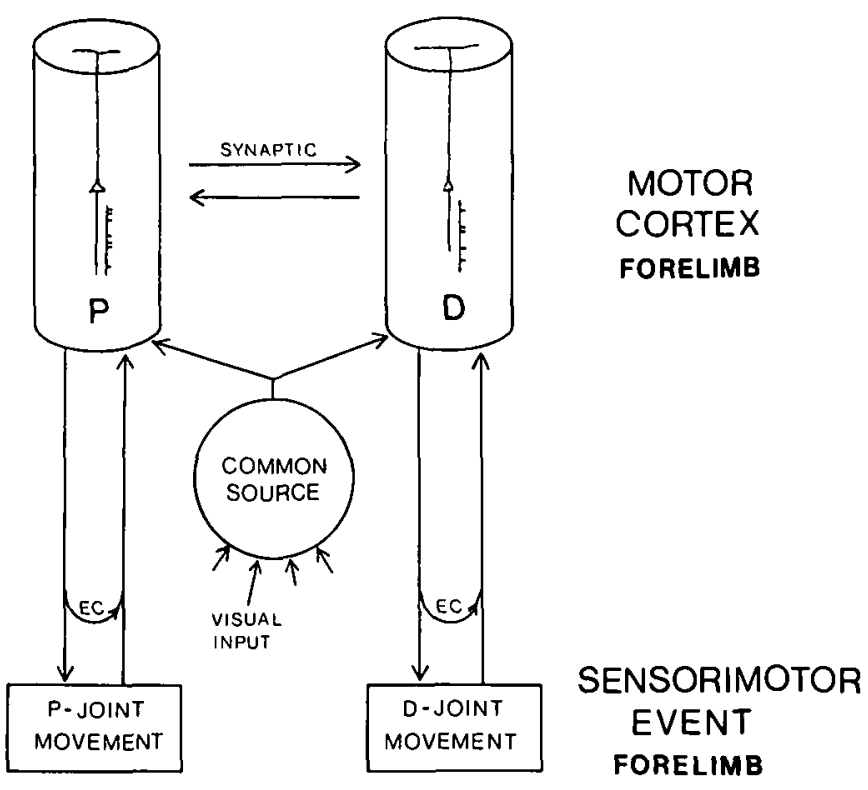

Figure 6 - Summary diagram of participation by motor cortical columns in a forelimb reaching movement. $P$ : columns controlling proximal limb part. D: distal. Output spike train of a neuron within each column is schematically shown beside each axon. See text.
All forelimb joints participated in the movement and all forelimb precentral regions evinced correlation. The latter occurred within a single joint zone, between adjacent joint zones or across one or two joint zones (Fig. 5A, Table 2). This result would be anticipated by the very nature of event-related correlation (Perkel et al., 1967) if the spatial representations of the forelimb event and the precentral neuron populations were coincident. Thus, the data strengthen the interpretation that such a coincidence is indeed present.

The data of Figure 3 indicate that the percentage of eventrelated pairs decrements with distance. This implies that the density of neurons correlated to a particular neuron is greatest near that neuron. We may infer that portions of the complex behavioural event are represented by portions of precentral cortex which are relatively contiguous. Moreover, some neurons are not involved in the forelimb event, which involves all joints, despite the fact that they are functionally coupled to a particular joint as determined by ICMS and sensory stimulation (Fig. 5A): Stated differently, the potential for use is not realized in all movement contexts. Rather, for a particular movement event, there appears to be selective involvement of patches of neurons containing cells which are within $3.5 \mathrm{~mm}$ of each other.

To further investigate the above interpretation, we added the variable of joint coupling to that of distance (Table 2, Fig. 5A). These data indicate event-related correlation across multiple 
joints. The maximum size of a zone in which event-related correlation was manifest was $3.5 \mathrm{~mm}$ along any axis (Figs. 3, 4, 5A). Within such a zone, strength of event-related correlation did not vary with distance (Fig. 4). In other words, for this multijoint event, strength of correlation was similar across the nested joint zones. It is of interest that the distance between finger and shoulder zones is $3.5-5.0 \mathrm{~mm}$ (Fig. 5A), which is of similar order of magnitude to the zone in which event-related correlation exists for this task.

\section{Comparison with Other Methodologies}

Several techniques are available to correlate cerebral function with a behavioural event. These include cerebral blood flow measurements (Roland et al., 1980), metabolic scans (Sokoloff, 1977; Raichle, 1979), optical imaging (Grimvald, 1984), and scalp recordings of electrical potentials (Netz et al., 1984) or magnetic fields (Kaufman and Williamson, 1982). All of these methods share the ability to produce topographic maps of extensive portions of brain. The first two have poor time resolution which limits their application to movement control paradigms. Scalp recording does not share this disadvantage, but has limited spatial resolution due to interposition of volume conductors of uncertain composition and spatial arrangement. Optical imaging and magnetoencephalography are each technically difficult, but potentially useful in specific applications. Cross correlation analysis with direct recording from cerebral neurons provides high degrees of both spatial and temporal resolution, and thus complements the above methods. The ability to detect shifts in correlation in a millisecond time frame makes this technique especially suitable for the study of movement control.

\section{Functional Significance}

A summary diagram incorporating the results of these cross correlation studies as well as earlier work is shown in Figure 6. A visual trigger which may be considered to act through intermediate anatomic networks, denoted as common sources, initially activates cells located in columns which control proximal forelimb muscles (Kwan et al., 1981). These columns participate in the generation of movement of proximal limb parts (Kwan et al., 1978; Murphy et al., 1982, 1985b). This movement activates sensory systems which project back to the same columns (Asanuma, 1975; Murphy et al., 1978). The 'proximal' columns (P) in turn synaptically interact over a ms time frame with columns controlling distal muscles (D) (Murphy et al., 1985a). The distal limb movement ensues and the process is completed.

The average time delay between the onsets of 'proximal' and 'distal' cortical cell discharges is about $60 \mathrm{~ms}$ in this task (Murphy et al., 1985b). This delay is composed largely of efferent delays of about 20-30 ms (Asanuma and Rosen, 1972; Murphy et al., 1980), and afferent delays of similar magnitude (Wong et al., 1980). The finding that $95 \%$ of all event-related interaction delays occur within $100 \mathrm{~ms}$ (Figure 2B) confirms this interpretation.

The proximal and distal columns share input from common sources (Murphy et al., 1985a). These common sources could include any parts of brain including sensory channels subserving visual triggers and the somatosensory inputs referred to above. In addition, the process of efference copy (EC) of the outputs of cortical columns upon sensory pathways, which is well known (Towe, 1973), probably contributes at many levels.
The combination of simplicity and sophistication in the control process for this forelimb reaching movement is remarkable. Of particular note is the way in which this process is attuned to environmental details perceived through the limb which executes the movement. It is hoped that these discoveries of motor cortical function may be of heuristic benefit in future studies of the role of other CNS regions in movement controls.

\section{ACKNOWLEDGEMENTS}

This research was supported by MRC of Canada. We thank $H$. Nguyen Huu for programming assistance.

\section{REFERENCES}

Allum JHJ, Hepp RMC and Gysin R (1982) Cross correlation analysis of interneuronal connectivity in the motor cortex of the monkey. Brain Research 231: 325-334.

Asanuma H (1975) Recent developments in the study of columnar arrangement of neurons within the motor cortex. Physiol Rev 55: 143-156.

Asanuma H and Rosen I (1972) Topographical organization of cortical efferent zones projecting to distal forelimb muscles in the monkey. Exp Brain Res 14: 243-256.

Cox DR and Lewis PAW (1966) The Statistical Analysis of Series of Events. Matheson, London.

Dayhoff JE and Gerstein GL (1983) Favored patterns in spike trains. II Application. J Neurophysiol 49: 1349-1363.

Dickson JW and Gerstein GL (1974) Interactions between neurons in auditory cortex of the cat. J Neurophysiol 37: 1239-1261.

Grimvald A (1984) Real time optical imaging of neuronal activity. TINS 7: $143-150$.

Harnett DL (1975) Introduction to statistical methods. 2nd Ed. AddisonWesley, Mass., pp 529-532.

Kaufman L and Williamson SJ (1982) Magnetic location of cortical activity. Ann N.Y. Acad Sci 388: 197-213.

Kwan HC, MacKay WA, Murphy JT and Wong YC (1978) Organization of precentral cortex in awake primates. II Motor outputs. J Neurophysiol 41: 1120-1131.

Kwan HC, MacKay WA, Murphy JT and Wong YC (1981) Distribution of responses to visual cues for movement in precentral cortex of awake primates. Neuroscience Letters 24: 123-128.

Lamarre Y, Busby L and Spidalieri G (1983) Fast ballistic arm movements triggered by visual, auditory and somesthetic stimuli in the monkey. I. Activity of precentral cortical neurons. J Neurophysiol 50: 1343-1358.

Lemon RN (1981) Functional properties of monkey motor cortex neurons receiving afferent input from the hand and fingers. J Physiol (Lond.) 311: 497-519.

Michalski A, Gerstein GL, Garkowska J and Tarnecki R (1983) Interactions between cat striate cortex neurons. Exptl Brain Res 51: 97-107.

Moore GP, Segundo JP, Perkel DH and Levitan H (1970) Statistical signs of synaptic interaction in neurons. Biophys J 10: 876-900.

Murphy JT, Kwan HC, MacKay WA and Wong YC (1978) Organization of precentral cortex in awake primates. III. Input-output coupling. J Neurophysiol 41: 1132-1139.

Murphy JT, Kwan HC, MacKay WA and Wong YC (1980) Physiologic basis for focal motor seizures and the Jacksonian "March" phenomena. Can J Neurol Sci 7: 79-85.

Murphy JT, Kwan HC, MacKay WA and Wong YC (1982a) Precentral unit activity correlated with angular components of a compound movement. Brain Res 246: 141-145.

Murphy JT, Kwan HC, MacKay WA and Wong YC (1982b) Activity of primate precentral neurons during voluntary movements triggered by visual signals. Brain Res 236: 429-449.

Murphy JT, Kwan HC and Wong YC (1985a) Cross correlation studies in primate motor cortex. I: Synaptic interaction and shared input. Can J Neurol Sci 12: 11-23.

Murphy JT, Kwan HC and Wong YC (1985b) Sequential activation of neurons in primate motor cortex during unrestrained forelimb movements. J Neurophysiol, in press. 
Netz J, Hamberg V, Grunewald-Zuberbier E and Grunewald G (1984) Event related changes of fast rhythmic EEG activity in a positioning movement task. Ann N.Y. Acad Sci 429: 483-488.

Perkel DH, Gerstein GL and Moore GP (1967) Neuronal spike trains and stochastic point processes. II. Simultaneous spike trains. Biophys J 7: 419.440 .

Raichle ME (1979) Quantitative in vivo autoradiography with positron emission tomography. Brain Research Rev 1: 47-68.

Roland PE, Skinhoj E, Lassen NA and Larsen B (1980) Different cortical areas in man in organization of voluntary movements in extrapersonal space. J Neurophysiol 43: 137-150.

Sokoloff L (1977) Relation between physiological function and energy metabolism in the central nervous system. J Neurochem 29: 13-25.
Tatton WG and Sokolove PG (1975) Analysis of postural motoneuron activity in crayfish abdomen. II. Coordination by excitatory and inhibitory connections between motoneurons. J Neurophysiol 38: 332-346.

Towe AL (1973) Somatosensory cortex, descending influences on ascending systems. In Iggo, A, ed, Handbook of Sensory Physiology. Somatosensory System, pp 701-718, N.Y., Springer-Verlag.

Wong YC, Kwan HC, MacKay WA and Murphy JT (1978) Spatial organization of precentral cortex in awake primates. I. Somatosensory inputs. J Neurophysiol 41: 1107-1119.

Wong YC, Kwan HC and Murphy JT (1980) Temporal characteristics of torque-triggered neuronal responses in primate precentral cortex. Can J Physiol Pharmacol 58: 778-786. 